\title{
Ameliorating Efficacy of Curcumin on Cadmium Induced Thyroid Dysfunction in Albino Rats
}

\author{
S. Sharma ${ }^{1}$ and C. Ahuja ${ }^{2 *}$ \\ ${ }^{1,2}$ Department of Zoology and Environmental Sciences, Punjabi University, Patiala-147002, Punjab, India \\ *Corresponding Author: chetnaahuja.in@gmail.com
}

Available online at: www.isroset.org

Received: 10/Feb/2019, Accepted: 22/Feb/2019, Online: 28/Feb/2019

\begin{abstract}
Cadmium (Cd) is one of the hazardous heavy metals as it causes various forms of physiological and hormonal imbalances. The aim of the present study was to investigate pharmacological effects of curcumin, a derivative of Curcuma longa Linn., in the prevention of oxidative stress induced by $\mathrm{CdCl}_{2}$ on the thyroid gland of albino rats. In this study, rats were divided into 5 groups ( $\mathrm{n}=5)$. Group 1 rats kept as control. Group 2 rats administered a single oral dose of $50 \mathrm{mg} / \mathrm{kg}$ body weight of $\mathrm{CdCl}_{2}$ on day 1 and left for 30 days. Group 3 rats were given an oral dose of $150 \mathrm{mg} / \mathrm{kg}$ body weight of curcumin daily for 30 days and kept as a positive control. Group 4 rats, acted as a post-treated group, administered a single oral dose of $50 \mathrm{mg} / \mathrm{kg}$ body weight of $\mathrm{CdCl}_{2}$ on day 1 and $150 \mathrm{mg} / \mathrm{kg}$ body weight of curcumin daily for the next 30 days. Group 5 rats, acted as a pretreated group, were given an oral dose of $150 \mathrm{mg} / \mathrm{kg}$ body weight of curcumin daily for 30 days and $50 \mathrm{mg} / \mathrm{kg}$ body weight of $\mathrm{CdCl}_{2}$ on last day. In rats, acute $\mathrm{CdCl}_{2}$ treatment caused increased oxidative stress, decreased SOD, CAT and irregularities in normal levels of serum hormones (T3, T4, and TSH). In curcumin supplemented rats, level of Cd-induced lipid peroxidation was significantly lowered, the activity of SOD and CAT were significantly increased and improved serum hormone levels were noticed, which shows that curcumin to some degree could alleviate the toxic effects of $\mathrm{CdCl}_{2}$.
\end{abstract}

Keywords-Cadmium, Curcumin, Thyroid, T3, T4, TSH, Oxidative Stress

\section{INTRODUCTION}

Environmental pollution is considered as man's greatest crime against himself as pollution of the ecosystem with industrial, agricultural and sewage effluents results in contamination of air, food and water with some toxic agents such as heavy metals which constitute a major public threat. Some metals are essential for life, others have unknown biological functions and some others have the potential to cause toxicity [1]. Heavy metals are persistent environmental contaminants since they cannot be degraded or destroyed easily from living systems.

Among the various heavy metals, Cadmium (Cd), 48th element in the periodic table with an atomic weight of 112.4, is one of the hazardous metals that is not physiologically or biochemically essential to organisms and is present in all components of our environment i.e. air, water and soil. It is unique among all the heavy metal toxicants because of its low dosage toxicity, long biological half-life and low rate of excretion from the body [2].

International Agency for Research on Cancer has classified $\mathrm{Cd}$ as a group I human carcinogen [3,4]. It is largely used in cadmium-based products such as nickel-cadmium batteries, television phosphors, stabilizer for polyvinyl chloride etc. Due to its brilliant orange color, it is extensively used as a pigment in paints, plasters and plastics [5]. It is known to be the most harmful heavy metal as it causes various forms of diseases such as osteomalacia, osteoporosis, hypertension, arteriosclerosis, anemia and cancer [6,7].

Cadmium, as an environmental pollutant, affects various tissues and organs. Once absorbed, $\mathrm{Cd}$ is rapidly cleared from blood but remains in various tissues [8]. It can accumulate in the body over many years because the body doesn't possess a homeostatic mechanism to keep $\mathrm{Cd}$ at constant level [9]. Long exposure to high or low doses of cadmium may cause biochemical and functional changes in some critical organs [10], where it causes many metabolic and histopathological changes, leading to various possible pathological conditions in both animals and human populations culminating in infertility and cancer of the reproductive tissues [11-13].

Thyroid gland, is an endocrine gland, whose follicular and parafollicular cell synthesize and secrete important regulatory hormones such as thyroxine (T4) and triiodothyronine (T3) which are necessary to maintain the 
metabolism of the cells [14]. Cd as a potential pollutant and an endocrine disrupting compound (EDC) [15,16], affect thyroid gland by accumulating in the mitochondria of thyroid follicular epithelial cells and inhibiting the synthesis and release of its hormones. Cd appears to be the largest single contributor to auto-immune thyroid disease [17-19].

In recent years, much attention has been given on the use of herbal medicines and their derivatives in healing different conditions related to toxicity [20]. There has been considerable public and scientific interest in the use of phytochemicals especially polyphenols derived from dietary components to combat human diseases due to their antioxidant, anti-inflammatory, anti-bacterial, anti-mutagenicity and anti-cancer properties [21].

Turmeric (Curcuma longa Linn.) belonging to family Zingiberaceae, is an imperative spice present in every Indian kitchen. It is traditionally used in India as a coloring and flavoring agent in food as well as for medicinal purposes [22]. It is usually used in most of the cooked preparations and is generally believed to fend off several ailments. It exhibits antitumor, anti-inflammatory and anti-infectious activities $[23,24]$.

Curcumin (Cur), a derivative of Curcuma, is the main active component of turmeric. Curcumin is among the best characterized natural polyphenols and is the prime yellow pigment extracted from turmeric. Curcumin has been given the designation of super antioxidant and has shown to possess a broad spectrum of biological and pharmacological activities, anti-inflammatory, antineoplastic, anti-mutagenic and anticancer effects [25]. It is found to be effective against several disorders including anorexia, coryza, cough, hepatic diseases and sinusitis [26,27]. The most important feature of curcumin is that it has no side effects despite being a therapeutic and antioxidant agent with multiple beneficial functions $[28,29]$. So, the aim of the present study is to evaluate the protective role of curcumin in $\mathrm{Cd}$ - induced oxidative stress on thyroid gland activity.

Rest of the paper is organized as follows, Section I contains the introduction of the study. Section II contains materials purchased and methods applied for the experiment. Section III contains the output of the experiment in the form of results with graphs. Section IV describes the discussion with reference to previous work done. Section $\mathrm{V}$ concludes research work and Section VI contains the acknowledgment.

\section{MATERIALS AND METHODS}

2.1 Source of Chemicals: Cadmium chloride $\left(\mathrm{CdCl}_{2}\right)$ and Curcumin (Cur) were purchased from Himedia Laboratories Pvt. Ltd., Mumbai. $\mathrm{CdCl}_{2}$ was dissolved in distilled water and administered to rats by oral gavage. An aqueous suspension of curcumin was made and administered orally to rats [30].
2.2 Procurement of Animals: 25 male wistar albino rats weighing 100- 200 grams were purchased from Disease Free Animal House, LUVAS, Hisar. Rats were housed in plastic cages with soft wood chips for bedding, acclimatized to the laboratory conditions for 15 days and fed with the standard rat feed in the form of pellets purchased from M/S Aashirwad Industries, Ltd., Chandigarh and water ad libitium.

2.3 Experimental Design: In the present study, Wistar albino rats were divided into 5 groups $(\mathrm{n}=5)$ and kept as designed protocol as follows:

- Group 1 (Control): Rats were kept as control.

- Group 2 (Cd): Rats were administered a single oral dose of $50 \mathrm{mg} / \mathrm{kg}$ body weight of $\mathrm{CdCl}_{2}$ on day 1 and left for 30 days.

- Group 3 (Cur): Rats were given an oral dose of $150 \mathrm{mg} / \mathrm{kg}$ body weight of curcumin daily for 30 days and kept as a positive control.

- Group 4 (Cd+Cur): Rats were given a single oral dose of $50 \mathrm{mg} / \mathrm{kg}$ body weight of $\mathrm{CdCl}_{2}$ on day 1 and $150 \mathrm{mg} / \mathrm{kg}$ body weight of curcumin daily for next 30 days and served as a post-treated group.

- Group 5 (pre Cur+Cd): Rats were given an oral dose of $150 \mathrm{mg} / \mathrm{kg}$ body weight of curcumin daily for 30 days and $50 \mathrm{mg} / \mathrm{kg}$ body weight of $\mathrm{CdCl}_{2}$ on the last day which served as a pre-treated group.

2.4 Serum Collection: 24 hours after the administration of the last dose, $2 \mathrm{ml}$ of blood from each rat was collected via retro-orbital venous plexus in clean dry centrifuge tubes, left for 20 minutes at room temperature to clot, centrifuged at $3000 \mathrm{rpm}$ for 5 minutes for separation of blood serum and quickly frozen at $-20^{\circ} \mathrm{C}$ till the assessment of various hormones (T3, T4 and TSH). Meanwhile, the animals were sacrificed by cervical dislocation. The thyroid gland was removed, freed of adipose tissue, blotted dry, weighed separately and processed for biochemical (MDA, SOD and CAT) investigations.

2.5 Estimation of T3, T4 and TSH: Serum total T3 (triidothyronine), T4 (thyroxine) and TSH (thyroid stimulating hormone) were assessed by ELISA reader using kits provided by Calbiotech Inc. USA according to the manufacturer's instruction [31].

2.6 Determination of MDA: The level of malondialdehyde (MDA), the end product of lipid peroxidation was evaluated by the method described [32].

2.7 Assay of Superoxide dismutase and Catalase Activity: Superoxide dismutase (SOD) and Catalase (CAT) activity were estimated according to previously described methods $[33,34]$.

2.8 Statistical analysis: Data was subjected to one-way analysis of variance (ANOVA) by using GraphPad PRISM 
version 7.03. Results are expressed as mean \pm S.D. Values were considered statistically significant at $p \leq 0.05$.

\section{RESULTS}

3.1 Body and organ weight: As evaluated from the present findings, body weight of the experimental animals gradually increased in all the treated groups but lesser weight gain was observed in Cd-exposed rats G2 as compared to control. Overall, the weight of the thyroid gland exhibited a significant decrease $(p<0.001)$ in all the treated groups compared to control group. Co-administration of curcumin with cadmium in post-treated and pre-treated rats revealed significantly higher values $(\mathrm{p}<0.001)$ when compared to intoxicated group G2. Positive control rats G3 revealed almost similar results compared to control (Fig. 1).

3.2 Hormonal Analysis: In the present study, 30 days after the acute exposure to $50 \mathrm{mg} / \mathrm{kg}$ body weight of $\mathrm{Cd}$, serum analysis revealed a significant decrease $(\mathrm{p}<0.0001)$ in $\mathrm{T} 3$ and $\mathrm{T} 4$ levels in $\mathrm{Cd}$ treated $\mathrm{G} 2$ group in comparison to control G1. On the other hand, T3 and T4 levels were increased significantly with $\mathrm{p}<0.0001$ in case of curcumin post-treated and pre-treated groups (G4 and G5) as compared to Cd treated G2 (Fig. 2 and 3).

The serum concentration of TSH was increased significantly $(\mathrm{p}<0.0001)$ in case of $\mathrm{Cd}$ treated group when compared to control group. The higher plasma level of TSH was decreased significantly $(p<0.0001)$ in groups G4 and G5 treated with curcumin as compared to $\mathrm{Cd}$ treated $\mathrm{G} 2$ group (Fig. 4).

Curcumin administered (G4 and G5) rats showed almost normal T3 levels ( $>0.05)$ when compared to control. G5 rats showed a normal serum T4 level $(p>0.05)$ when compared to control but a significant difference in plasma T4 $(\mathrm{p}<0.001)$ concentration was observed in G4 rats as compared to control (Fig. 2 and 3). However, treatment with curcumin in G4 and G5 rats did not normalize serum TSH levels compared to control group but co-administration of curcumin could slightly decrease the elevated TSH levels in these groups (Fig. 4).

3.3 Biochemical Analysis: MDA concentration in the thyroid tissue was used as a measure of lipid peroxidation. The results of the present study showed a significant increase $(p<0.0001)$ in MDA content in the thyroid tissue of $\mathrm{Cd}$ - exposed rats $(\mathrm{G} 2)$ when compared to control. But the values of MDA content in case of G4 and G5 rats exhibited a significant decrease $(\mathrm{p}<0.0001)$ in MDA content when compared with the $\mathrm{Cd}$ treated rats $\mathrm{G} 2$. (Fig. 5).

Cd-exposed rats $\mathrm{G} 2$ expressed a significant decrease in the activity of antioxidant enzymes SOD $(p<0.0001)$ and CAT $(\mathrm{p}<0.0001)$ in thyroid in comparison to control. A significant increase ( $\mathrm{p}<0.0001)$ was observed in SOD and CAT activity in curcumin supplemented groups when compared to $\mathrm{Cd}$ exposed group (Fig. 6 and 7).

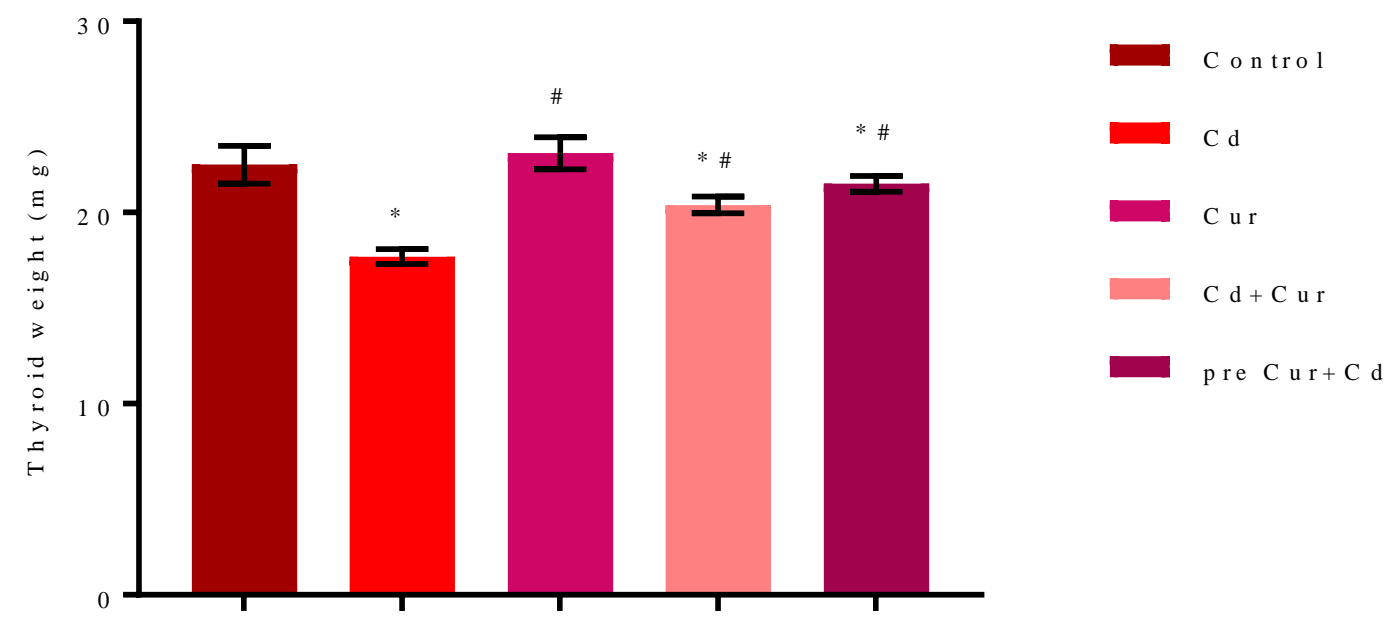

Figure 1. Mean weight of thyroid gland in control and experimental rats. Results are expressed as mean \pm S.D. $\left({ }^{*} \mathrm{p} \leq 0.05\right.$ vs control, $\# \mathrm{p} \leq 0.05$ vs $50 \mathrm{mg} / \mathrm{kg}$ Cd group) S.D. = Standard Deviations; $\mathrm{p}=$ probability 


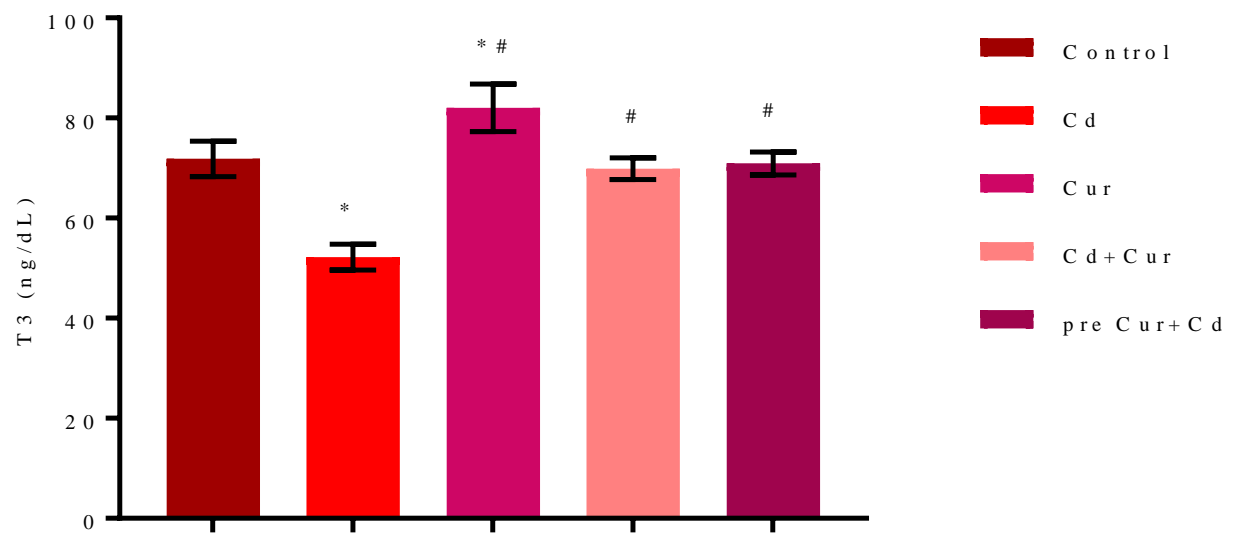

Figure 2. Serum $\mathrm{T} 3$ concentration in control and experimental rats. Results are expressed as mean \pm S.D. $\left({ }^{*} \mathrm{p} \leq 0.05\right.$ vs control, $\# \mathrm{p} \leq 0.05$ vs $50 \mathrm{mg} / \mathrm{kg}$ Cd group). S.D. $=$ Standard Deviations; $\mathrm{p}=$ probability

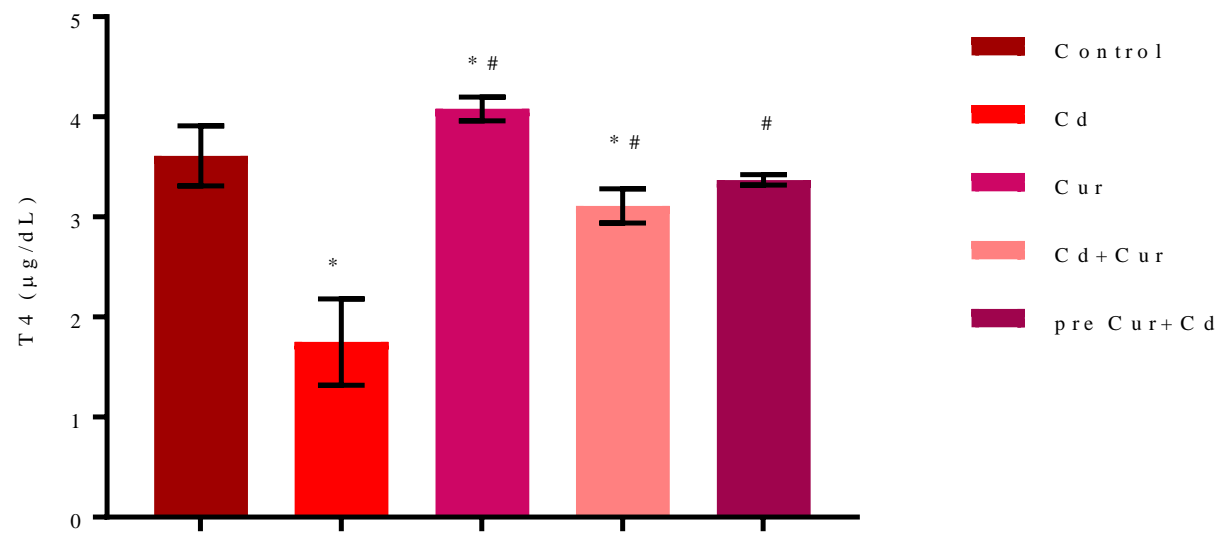

Figure 3. Serum T4 concentration in control and experimental rats. Results are expressed as mean \pm S.D. ( ${ }^{*} \mathrm{p} \leq 0.05$ vs control, $\# \mathrm{p} \leq 0.05 \mathrm{vs} 50 \mathrm{mg} / \mathrm{kg}$ Cd group). S.D. = Standard Deviations; $\mathrm{p}=$ probability
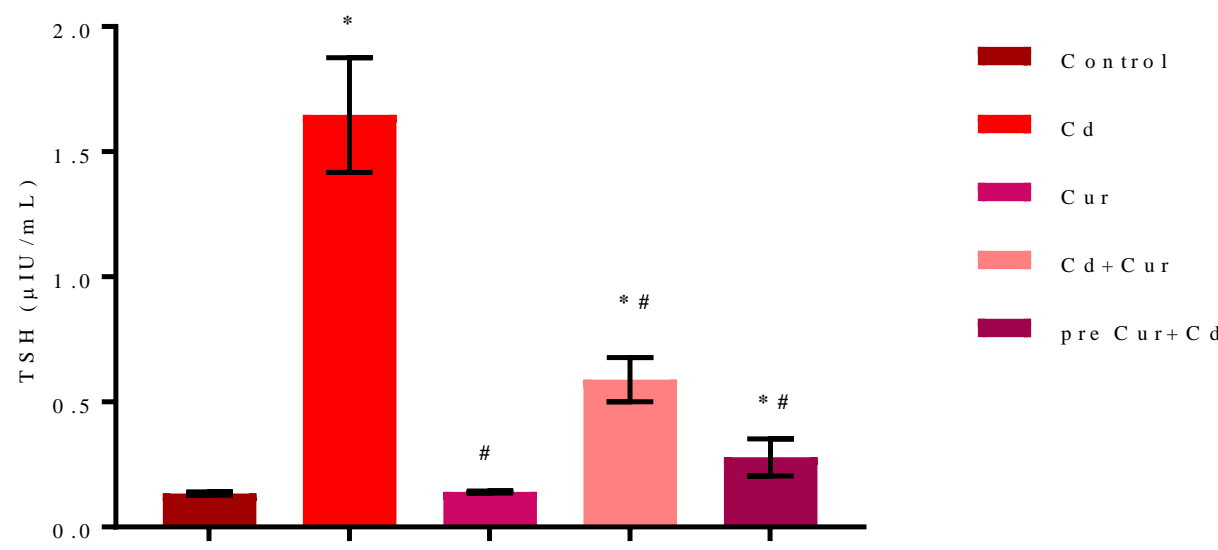

Figure 4. Serum TSH concentration in control and experimental rats. Results are expressed as mean \pm S.D. $\left({ }^{*} \mathrm{p} \leq 0.05\right.$ vs control, $\# \mathrm{p} \leq 0.05$ vs $50 \mathrm{mg} / \mathrm{kg}$ Cd group). S.D. = Standard Deviations; $\mathrm{p}=$ probability 


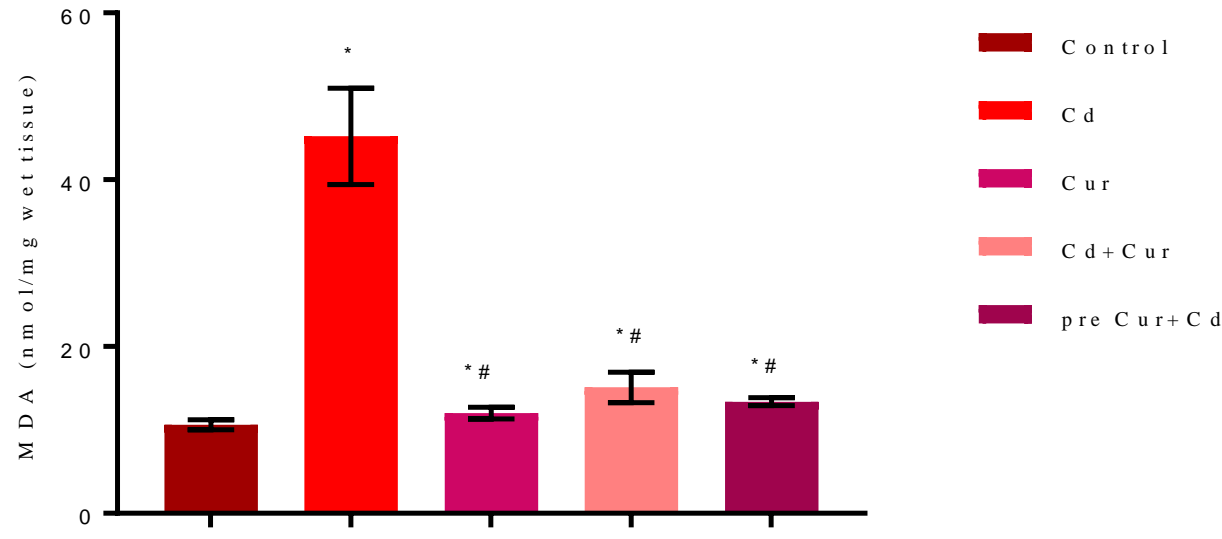

Figure 5. Lipid peroxidation, expressed as MDA content, in the thyroid homogenates of the control and experimental rats. Results are expressed as mean \pm S.D. $(* \mathrm{p} \leq 0.05$ vs control, $\# \mathrm{p} \leq 0.05$ vs $50 \mathrm{mg} / \mathrm{kg}$ Cd group). S.D. $=$ Standard Deviations; $\mathrm{p}=$ probability

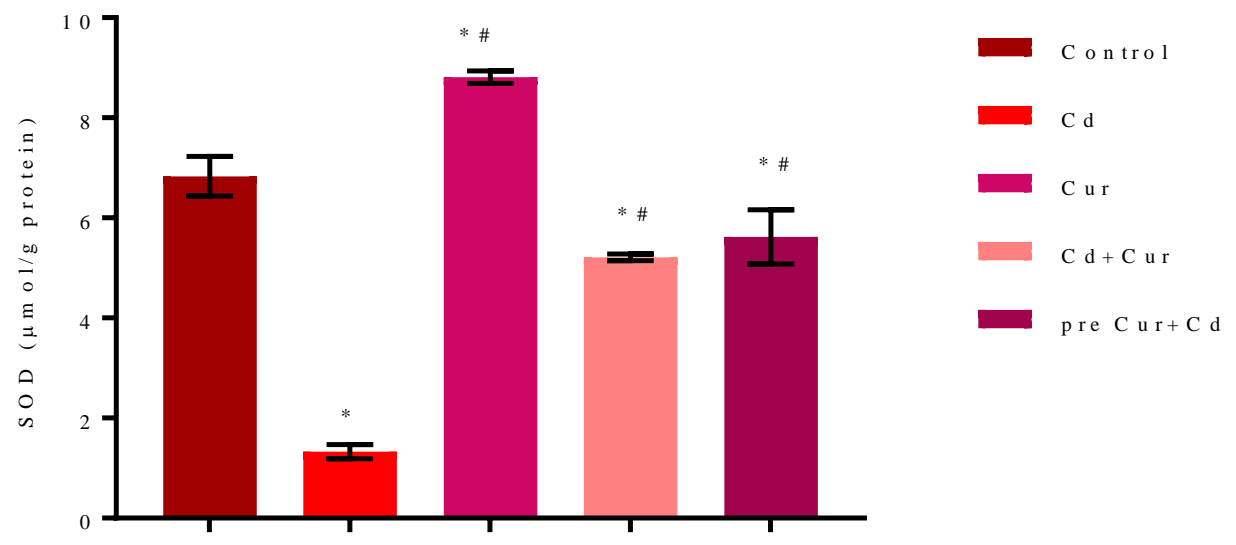

Figure 6. Superoxide dismutase (SOD) activity in the thyroid homogenates of the control and experimental rats. Results are expressed as mean \pm S.D. ( $* \mathrm{p} \leq 0.05$ vs control, $\# \mathrm{p} \leq 0.05$ vs $50 \mathrm{mg} / \mathrm{kg}$ Cd group). S.D. $=$ Standard Deviations; $\mathrm{p}=$ probability

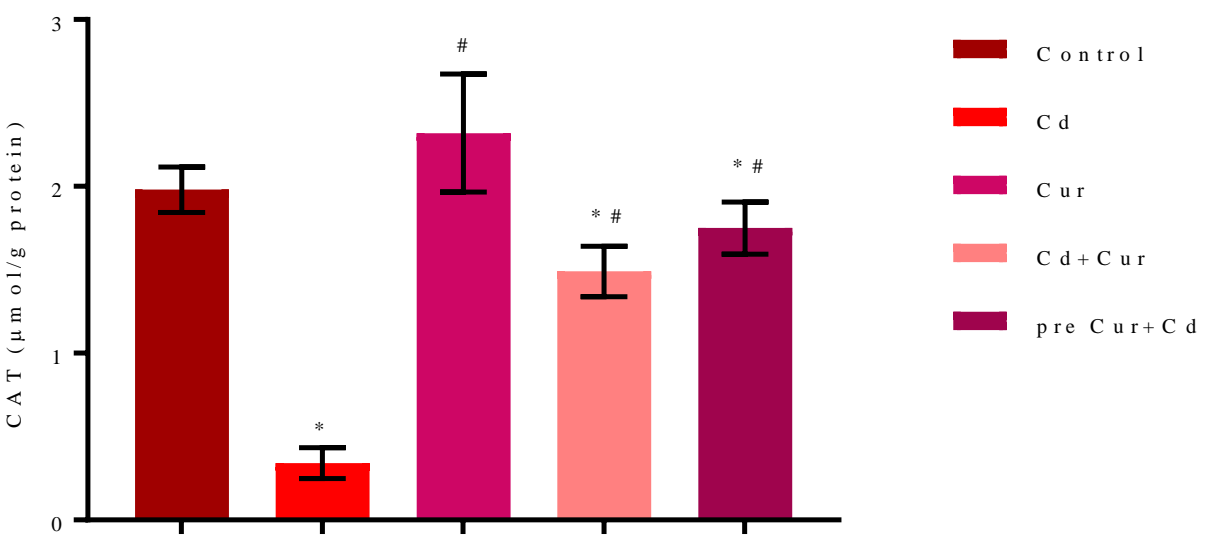

Figure 7. Catalase (CAT) activity in the thyroid homogenates of the control and experimental rats. Results are expressed as mean \pm S.D. (* $\leq 0.05$ vs control, $\# p \leq 0.05$ vs $50 \mathrm{mg} / \mathrm{kg}$ Cd group). S.D. $=$ Standard Deviations; $\mathrm{p}=$ probability 


\section{DISCUSSION}

Human beings are mostly exposed to cadmium through industrial aerosols, waste waters from extraction mines, cigarette smoke, phosphate-based fertilizers and accidental ingestion of contaminated dust or soil [35]. Through the process of bioaccumulation and due to the long half-life of the $\mathrm{Cd}$, which requires 20 years to completely metabolize in humans [36], acute or chronic exposure to $\mathrm{Cd}$ can lead to oxidative stress in organs such as liver, kidney, bone and testes in experimental animals [37-39]. Oxidative stress occurs when there are too many free radicals and too much cellular damage which exceeds the body's natural defense systems. Antioxidants are natural substances which clean up free radicals within the cells. Some studies have reported that non-enzymatic polyphenolic antioxidants such as curcumin could alleviate oxidative stress [40]. The purpose of the present study was to find out the efficacy of curcumin against $\mathrm{CdCl} 2$ induced oxidative stress in the thyroid gland of albino rats.

For maintaining important bodily functions such as metabolism, growth, reproduction etc., thyroid hormones play an essential role and are regulated by pituitary and hypothalamus [41]. For instance, when the level of thyroid hormones falls in the blood, hypothalamus secretes thyrotropin releasing hormone (TRH) which in turn stimulates anterior pituitary to release thyroid stimulating hormone (TSH) which further controls the secretion of triidothyronine (T3) and thyroxine (T4) [42]. Some studies reported alteration in the activities of thyroid and parathyroid glands as well as disruption in the secretion of their hormones after accumulation of $\mathrm{Cd}$ in them [43].

In the present study, Cd-exposed rats (G2) experienced hypothyroidism which was evidenced biochemically by significant decrease in serum $\mathrm{T} 3$ and $\mathrm{T} 4$ levels and significant increase in serum TSH level when compared to control. Many studies have shown the production of reactive oxygen species (ROS) in hypothyroidism [44,45], which may be the principal cause of low $\mathrm{T} 3$ and $\mathrm{T} 4 . \mathrm{Cd}$ accumulates in the mitochondria of follicular epithelial cells of thyroid tissue, disturbing oxidative phosphorylation and due to low energy production, inhibits the synthesis and release of thyroid hormones [46].

The results of the present study are in agreement to the results of previous studies who reported that precursor of the thyroid hormones $\mathrm{T} 3$ and $\mathrm{T} 4$ is a glycoprotein called thyroglobulin which is synthesized by the follicular cells and stored in the lumen of the follicles [47]. Cadmium accumulation in these cells may interfere with the release of $\mathrm{T} 3$ and T4. Other studies suggested that low T3 and T4 levels occur due to reduction in the activity of the enzyme called 'ORD' (Outer Ring Deiodinase) present in liver cells, which convert $\mathrm{T} 4$ into more biologically active form, T3 [48]. Lower activity of this enzyme could play a critical role in normal circulating serum T3 and T4 levels.
Further, a significant higher serum concentration of TSH was found in Cd-exposed rats $(\mathrm{G} 2)$ which was not able to produce enough $\mathrm{T} 3$ and $\mathrm{T} 4$. Studies suggested that $\mathrm{Cd}$ induces irregularities in the synthesis of thyroid hormones at pituitary level which produces more TSH in response to low serum concentration of T3 and T4 [49].

In the present study, a significant elevation in MDA concentration and significant reduction in the activities of SOD and CAT were observed in Cd treated rats (G2) when compared to control rats (G1) which indicates that thyroid antioxidant defense mechanism fails to protect the thyroid gland from oxidative stress produced by $\mathrm{Cd}$. Oxidative stress occurs due to an imbalance between intracellular production ROS and cellular antioxidant defense system [50]. Cells protect themselves against oxidative damage by network of enzymes such as superoxide dismutase (SOD) that catalyzes the breakdown of superoxide anion into oxygen $\left(\mathrm{O}_{2}\right)$ and hydrogen peroxide $\left(\mathrm{H}_{2} \mathrm{O}_{2}\right)$ [51,52]. Further, catalase converts $\mathrm{H}_{2} \mathrm{O}_{2}$ into oxygen and water thereby protecting the cells from the oxidative damage [53]. Since, $\mathrm{Cd}$ produces its toxicity by interacting with lipid membranes which caused high concentration of MDA in the thyroid gland [54]. The reduction in the activities of SOD and CAT could be due to the production of free radicals in the $\mathrm{Cd}$ exposed rats and due to the replacement of zinc $(\mathrm{Zn})$ or magnesium $(\mathrm{Mg})$ of the enzyme SOD by $\mathrm{Cd}$, changing its structure from $\mathrm{Cu} / \mathrm{Zn}-\mathrm{SOD}$ to $\mathrm{Cu} / \mathrm{Cd}-\mathrm{SOD}$, creating an inactive form of this enzyme [55,56], which may have failed to protect the cells from oxidative damage.

Hypothyroidism, is frequently treated with iodine supplements or thyroid hormone replacement therapy. Naturally occurring substances reinforce thyroid activity either by increasing the production of thyroid hormones or screening it from injury. In our experiment, post and pretreated group of rats (G4 and G5) with curcumin revealed significant higher serum values of $\mathrm{T} 3, \mathrm{~T} 4$ and significant lower values of TSH when compared to Cd-exposed rats (G2) which shows that curcumin has the ability to reverse the toxic effects of $\mathrm{Cd}$ to some extent and prevents oxidative damage by free radical trapping capacity. Moreover, two methoxylated phenols and enol form of $\beta$-diketone in the curcumin are responsible for free radical quenching ability which in turn acts as a chain-breaking antioxidant [57].

In Cd-induced toxicity, lipid peroxidation is the main event which give rise to ROS. But in curcumin treated rats G4 and G5, a significant decrease in the MDA content and significant increase in SOD and CAT activity were observed when compared to $\mathrm{Cd}$-exposed group $\mathrm{G} 2$ which confirms curcumin to be an effective antioxidant against Cd-induced tissue damage. Furthermore, studies suggested that curcumin scavenges lipid peroxyl radicals before they damage lipid membranes or by modifying the process of lipid peroxidation and boosting the activities of antioxidant enzymes $[58,59]$. 


\section{CONCLUSION}

We undertook the present study to evaluate the efficacy of curcumin in Cd-induced oxidative stress in thyroid gland activity. Our results indicate that oral administration of an acute dose of $\mathrm{CdCl}_{2}$ could inhibit the release of $\mathrm{T} 3$ and $\mathrm{T} 4$ even in the presence of elevated TSH which could be due to the enhanced generation of ROS resulting in depletion of antioxidant enzymes SOD and CAT causing failure of thyroid antioxidant defense system. However, supplementation of curcumin ameliorates $\mathrm{CdCl}_{2}$ induced thyroid dysfunction to some extent.

\section{ACKNOWLEDGEMENT}

The authors gratefully acknowledge the Institutional Ethical committee for permitting the research work on rats. Also, the facilities provided by the Department of Zoology and Environmental Sciences, Punjabi University, Patiala, to carry out the research studies are truly appreciated.

\section{REFERENCES}

[1]. M. Col, C. Col, A. Soran, “Arsenic related Bowen's Disease, Palmer Keratosis, and Skin Cancer", Environmental Health Perspectives, Vol. 107, pp.687-689, 1999.

[2]. O. Barbier, G. Jacquillet, M. Tauc, M. Cougnon, "Effect of cadmium on, and handling by, the kidney", Nephron Physiology, Vol.99, Issue.4, pp.105-110, 2005.

[3]. M.P. Waalkes, "Review Cadmium carcinogenesis", Mutation Research, Vol.533, pp. 107-120, 2003.

[4]. M. Waisberg, P. Joseph, B. Hale, D. Beyersmann, "Molecular and cellular mechanisms of cadmium carcinogenesis: a review”, Toxicology, Vol.192, pp.95-117, 2003.

[5]. P. Singh, K. Deora, V. Sankhla, P. Mogra, "Curcumin rendered protection against cadmium chloride induced testicular damage in Swiss albino mice”, Journal of Cell and Molecular Biology, Vol.10, Issue.2, pp.31-38, 2012.

[6]. A. Bernard, "Cadmium and its adverse effects on human health”, Indian Journal of Medical Research, Vol.128, No.4, pp.557-564, 2008.

[7]. A.W. Obianime, I.I. Roberts, "Antioxidants, cadmiuminduced toxicity, serum biochemical and histological abnormalities of the kidney and testes of the male wistar rats", Nigerian Journal of Physiological Sciences, Vol.24, Issue.2, pp. 177-185, 2009.

[8]. B.I. Ognjanovic et al., "Protective influence of vitamin E on antioxidant defense system in the blood of rats treated with cadmium", Physiological Research, Vol.52, Issue.5, pp.563570, 2003

[9]. A. Nasri, "Heavy metals, sources, symptoms, testing and treatment", www. Nasrichelation. com/pages/treatments/ heavy metals. htm: (1-9), 2006.
[10]. A. Grosicki, B. Kowalski, "Whole body and organ retention of cadmium after repeated administration to rats", Bulletin of the Veterinary Institute in Pulawy, Vol. 46, pp. 143-147, 2002.

[11]. M. Al-Azemi, F.E. Omu, E.O. Kehinde, J.T. Anim, A.A. Oriowo, A.E. Omu, "Lithium protects against toxic effects of cadmium in the rat testes" Journal of Assisted Reproduction and Genetics, Vol.27, Issue.8, pp.469-476, 2010.

[12]. D.K. Rekha, Y. Tripathi, C.V. Raghuveer, R.P. Sheila, C. Ramaswamy, K. Priya, "Role of vitamin $C$ as an antioxidant in cadmium chloride induced testicular damage", International Journal of Applied Biology and Pharmaceutical Technology, Vol.2, No.3, pp.484-488, 2011.

[13]. M. Chandel, G.C. Jain, "Toxic effects of transition metals on male reproductive system: A review", Journal of Environmental and Occupational Science, Vol.3, Issue.4, pp.204-213, 2014.

[14]. D. Dieter, E. Joanne, "Textbook of Veterinary Histology", $5^{\text {th }}$ edition, Waverly Company, Paris, Hong Kong, Sydney, Tokyo, 1998.

[15]. L. Jarup, A. Akesson, "Current status of cadmium as an environmental health problem", Toxicology and Applied Pharmacology, Vol.238, pp.201-208, 2009.

[16]. C.Y. Cheng, E.W.P. Wong, P.P.Y. Lie, M.W.M. Li, L. Su, E.R. Siu, "Environmental toxicants and male reproductive function”, Spermatogenesis, Vol.1, pp.2-13, 2011.

[17]. P. Gupta, A. Kar, "Cadmium induced thyroid dysfunction in chicken: hepatic type I iodothyronine 5\%-monodeiodinase activity and role of lipid peroxidation", Comparative Biochemistry and Physiology, Vol. 123, Issue.1, pp.39-44, 1999.

[18]. M. Pilat, B. Sawicki, M. jakoniuk, "Effect of administration of cadmium on the rat thyroid radioimmunological and immunohistochemical studies", Folia Histochemica et Cytobiologica, Vol.40, Issue.2, pp.189-190, 2002.

[19]. M. Pilat, M. Brzoska, B. Sawicki, "Histological evaluation of the thyroid structure after coexposure to cadmium and ethanol", Roczniki Akademii Medycznej w Bialymstoku, Vol.49, pp.1-152, 2004.

[20]. B.M. Lee, K.K. Park, "Beneficial and adverse effects of chemopreventive agents”, Mutation Research, Vol.523-524, pp.265-278, 2003.

[21]. K.S. Parvathy, P.S. Negi, P. Srinivas, "Antioxidant, antimutagenic and antibacterial activities of curcumin- $b$ diglucoside”, Food Chemistry, Vol.115, pp.265-271, 2009.

[22]. H.P. Ammon, M.A. Wahl, "Pharmacology of Curcuma longa”, Planta Medica, Vol. 57, pp.1-7, 1991.

[23]. I. Brouet, H. Oshimima, "Curcumin, an antitumor promoter and anti-inflammatory agent, inhibits induction of nitric oxide synthase in activated macrophages", Biochemical and Biophysical Research Communications, Vol.206, pp.533540, 1995.

[24]. A. Duvoix et al., "Chemopreventive and therapeutic effects of curcumin”, Cancer Letters, Vol.233, pp.181-90, 2005. 
[25]. R.S. Naik, A.M. Mujumdar, S.Ghaskadbi, "Protection of liver cells from ethanol cytotoxicity by curcumin in liver slice culture in vitro", Ethnopharmacology, Vol.95, pp.31-37, 2004.

[26]. N. Tirkey, G. Kaur, K. Chopra, "Curcumin, a Diferuloylmethane, Attenuates Cyclosporine-Induced Renal Dysfunction and Oxidative Stress in Rat Kidneys", BMC Pharmacology, Vol.5, pp.1-15, 2005.

[27]. I. Rahman, S.K. Biswas, P.A. Kirkham, "Regulation of Inflammation and Redox Signaling by Dietary Polyphenols", Biochemical Pharmacology, Vol.72, Issue.11, pp.1439-1452, 2006.

[28]. B. Joe, B.R. Lokesh, "Role of capsaicin, curcumin and dietary $n-3$ fatty acids in lowering the generation of reactive oxygen species in rat peritoneal macrophages", Biochemica et Biophysica Acta, Vol.1224, pp.255-263, 1994.

[29]. B. Joe, M. Vijaykumar, B.R. Lokesh, "Biological properties of curcumin-cellular and molecular mechanisms of action", Critical Reviews in Food Science and Nutrition, Vol.44, pp.97-111, 2004.

[30]. R. Kamel, A.A.A. Hashim, S.A.E. Ali, "Palliative Effect of Curcumin on Stz-Induced Diabetes in Rats", International Journal of Pharmacy and Pharmaceutical Sciences, Vol.6, pp.558-563, 2014.

[31]. J.C. Agharanya, "Clinical usefulness of ELISA technique in the assessment of thyroid function", Western African Journal of Medicine, Vol.9(4), pp.258-263, 1990.

[32]. K.M. Wilbur, F. Bernheim, O.W. Shapiro, "The thiobarbituric acid reagent as a test for the oxidation of unsaturated fatty acids by various agents", Archives of Biochemistry, Vol.24, pp.305-313, 1949.

[33]. K. Das, L. Samantha, G.B. Chinoy, "A modified spectrophotometric assay for superoxide dismutase using nitrite formation by superoxide radicals", Indian Journal of Biochemistry and Biophysics, Vol.37, pp.201-204, 2000.

[34]. H.E. Aebi, "Catalase. In: Methods of Enzymatic Analysis", Bergmeyer, H.U., Ed., Verlag Chemie, Weinhem, Vol.3, pp.273- 286, 1983.

[35]. P. Sengupta, "Environmental and occupational exposure of metals and their role in male reproductive functions", Drug and Chemical Toxicology, Vol. 36, Issue.3, pp.353-368, 2013.

[36]. B. Georgescu, C. Georgescu, S. Daraban, A. Bouaru, S. Pascalau, "Heavy Metals Acting as Endocrine Disrupters", Scientific Papers: Animal Science and Biotechnologies, Vol.44, No.2, pp.89-93, 2011.

[37]. L. Saïd, M. Banni, A. Kerkeni, K. Saïd, I. Messaoudi, "Influence of combined treatment with zinc and selenium on cadmium induced testicular pathophysiology in rat", Food and Chemical Toxicology, Vol.48, pp.2759-2765, 2010.

[38]. S. Sharma, P. Vijaya, "Protective Role of Lycopene against Cadmium Induced Haematological Changes in Swiss Albino Mice”, Asian Journal of Biomedical and Pharmaceutical Sciences, Vol.5, Issue.49, pp.17-20, 2015.
[39]. S. Kaur, S. Sharma, "A histometric study to assess preventive action of ascorbic acid and garlic on cadmium induced hepatotoxicity in albino mice", International Journal of Pharmaceutical and Phytopharmacological Research, Vol.5, Issue.3, pp.8-14, 2015.

[40]. F. Gultekin, N. Delibas, S. Yasar, I. Kilinc, "In vivo changes in antioxidant systems and protective role of melatonin and combination of vitamin $C$ and vitamin $E$ on oxidative damage in erythrocytes induced by chlorpyrifos-ethyl in rats”, Archives of Toxicology, Vol.75, pp.88-96, 2001.

[41]. K. Ito, Y. Kagaya, H. Shimokawa, "Thyroid hormone and chronically unloaded hearts", Vascular Pharmacology, Vol.52(3-4), pp.138-141, 2010.

[42]. M. Sukkar, M. Ardawi, H. El-Munshid, "Concise Human Physiology", $2^{\text {nd }}$ edition, USA. 2000.

[43]. B. Pilat-Marcinkiewicz, M.M. Brzoska, J. MoniuszkoJakoniuk, "Thyroid and Parathyroid Function and Structure in Male Rats Chronically Exposed to Cadmium”, Polish Journal of Environmental Studies, Vol.17, Issue.1, pp.113120, 2008.

[44]. E. Sarandol, S. Ta, M. Dirican, Z. Serdar, "Oxidative stress and serum paraoxonase activity in experimental hypothyroidism: effect of vitamin E supplementation”, Cell Biochemistry and Function, Vol.23, pp.1-8, 2005.

[45]. H. Erdamar et al., "The effect of hypothyroidism, hyperthyroidism, and their treatment on parameters of oxidative stress and antioxidant status" Clinical Chemistry and Laboratory Medicine, Vol.46, Issue.7, pp.1004-1010, 2008.

[46]. M. Yoshizuka et al., "Cadmium toxicity in the thyroid gland of pregnant rats", Experimental and Molecular Pathology, Vol.55, pp.97-104, 1991.

[47]. Lin, J.D, "Thyroglobulin and human thyroid cancer", Clinica Chimica Acta, Vol.388(1-2), pp.5-21, 2008.

[48]. L.L. Amma, C.Z. Wong, B. Venstrom, D. Forrest, "Distinct tissue specific roles for thyroid hormone receptors $\beta$ and $\alpha-$ in regulation of type 1-deiodinase expression", Molecular Endocrinology, Vol.15, Issue.3, pp.467-475, 2001.

[49]. B. Pilat-Marcinkiewicz, M.M. Brzoska, B. Sawicki, J. Moniuszko-Jakoniuk, "Structure and function of thyroid follicular cells in female rats chronically exposed to cadmium", Bulletin of the Veterinary Institute in Pulawy, Vol.47, pp.157-163, 2003.

[50]. D.D. Mruk, B. Silvestrini, M.Y. Mo, C.Y. Cheng, "Antioxidant superoxide dismutase - a review: its function, regulation in the testis and role in male fertility", Contraception, Vol.67, pp.305-311, 2002.

[51]. J. Banniste, W. Bannister, G. Rotilio, "Aspects of the structure, function, and applications of superoxide dismutase”, CRC Critical Reviews in Biochemistry, Vol.22, pp.111-180, 1987.

[52]. I. Zelko, T. Mariani R. Folz, "Superoxide dismutase multigene family: A comparison of the CuZn-SOD (SOD1), Mn-SOD (SOD2), and EC-SOD (SOD3) gene structures, 
evolution, and expression", Free Radical Biology and Medicine, Vol.33, pp.337-349, 2002.

[53]. P. Chelikani, I. Fita, P.C. Loewen, "Diversity of structures and properties among catalases", Cellular and Molecular Life Sciences, Vol.61, pp.192-208, 2004.

[54]. E. Casalino, C. Sblano, L. Clemente, "Enzyme activity alteration by cadmium administration to rats: the possibility of iron involvement in lipid peroxidation", Archives of Biochemistry and Biophysics, Vol.346, pp.171-179, 1997.

[55]. K. B. Jacobson, J. E. Turner, "The interaction of cadmium and certain other metal ions with proteins and nucleic acids", Toxicology, Vol.16, pp.1-37, 1980.

[56]. R. Bauer, I. Demeter, V. Hasemann, T. Johanson, "Structural properties of the zinc site in $\mathrm{Cu}, \mathrm{Zn}$-superoxide dismutase; perturbed angular correlation of gamma ray spectroscopy on the $\mathrm{Cu}, 111 \mathrm{Cd}$-superoxide dismutase derivative”, Biochemical and Biophysical Research Communications, Vol.94, pp.1296-1302, 1980.

[57]. T. Masuda, T. Maekawa, K. Hidaka, H. Bando, Y. Takeda, H. Yamaguchi, "Chemical studies on antioxidant mechanisms of curcumin: analysis of oxidative coupling products from curcumin and linoleate", Journal of Agriculture and Food Chemistry, Vol.49, pp.2539-2547, 2001.

[58]. B. Halliwell, J.M.C. Gutteridge, "Free Radicals in Biology and Medicine”, Oxford University Press Inc, New York, Vol.3, pp.105-245, 2002.

[59]. C. Kalpana, V.P. Menon, "Modulatory effects of curcumin on lipid peroxidation and antioxidant status during nicotineinduced toxicity", Polish Journal of Pharmacology and Pharmacy, Vol.56, pp.581-586, 2004. 